commoner and some of the less common conditions are discussed and illustrated. Lymphangiography is not discussed. The illustrations are mostly good, although the few films of abdominal aortograms are rather poor. There is a good bibliography.

This is a book mainly for the radiologist, and one of the best of its kind in this particular field. Radiologically the abdomen, particularly abdominal masses, is a very difficult problem and one is confident that this book will go a long way towards helping the radiologist out of his difficulties.

\section{Martini's Principles and Practice of Physical Diagnosis}

Revised by Yale KNeEland JR., M.D. and Robert F. Loeb, M.D. Third Edition. Pp. xv + 275, illustrated. London: Pitman Medical. Philadelphia: J. B. Lippincott. I962. 40s.

' This book is dedicated to teaching the essentials of seeing, hearing and feeling in their relation to the body in health and disease'. Thus Paul Martini aptly describes this small book, which has been extensively revised, after nearly 30 years, by Drs. Kneeland and Loeb of the Presbyterian Hospital, New York City. The section on the examination of the heart has been made much more detailed. A new chapter deals with a suggested procedure for the complete physical examination of a patient. It is an outline of the procedure currently used in the author's own hospital and differs from that used in many English hospitals. There are only three photographs, which illustrate palpation of the abdomen, but the 26 figures and diagrams are clearly drawn.

After a 50 page section on the general examination of the body, the authors describe the detailed physical diagnosis by systems, including relevant anatomy and physiology, and discuss the physical findings in relation to common disease. A more detailed description of the neurological examination would be an improvement, as clinical students, in this country, have studied the anatomy and physiology of the central and peripheral nervous system in detail.

In general the statements about which one would differ are points of emphasis rather than detail. For instance does every general physician in this country make a cervical smear for exfoliative cytology study, as part of a routine examination of an adult female? The roseola of typhoid is referred to in two sections, being mentioned in the first paragraph in the inspection of the abdomen. Students will see few cases of typhoid in this country.

This book which is of octavo size, has a clear print, is easily read and will be of interest to students just starting their clinical course.

\section{Pulmonary Structure and Function Ciba Foundation Symposium}

Editors: A. V.S. DE REUCK, M.SC., D.I.C., A.R.C.S., and Maeve O'Connor, B.A. Pp. xv +403 , with ror illustrations. London: J. \& A. Churchill. r962. 54s.

The requirements of aviation in the Second World War drew many research workers into respiratory physiology and for the last two decades the subject has made extraordinary progress. At times it has almost lost contact with structure and at times it has threatened to lose contact with reality. The symposium held at the Ciba Foundation last year therefore provided a very important opportunity to review the significant develop- ments in pulmonary function and relate them to structure. The symposium followed the well-known Ciba pattern in that a small group of leading workers was gathered together from all over the world. Each of the chosen participants gave a review of his field and this review appears in the book as a chapter. The topic was then discussed by the group as a whole; this discussion appearing at the end of the chapter. The quality of the contributions is exceptionally high even by the standards of the Ciba symposia. It is invidious to select individual contributions but I was particularly impressed by the contribution on the mechanics of the respiratory structures in which Mead dealt with the fascinating problem of alveolar stability; the electronmicroscopic structure as reviewed by Looslie and Schulz and the processes of gas exchange in the pulmonary capillaries as reviewed by Forster. The book is, of course, very well edited and very well produced. Anybody working in pulmonary anatomy, physiology, pathology or medicine will want to own this book and people in many other fields are strongly advised to read it.

\section{The Actinomycetes}

\section{Volume III: Antibiotics of Actinomycetes}

S. A. Waksman and H. A. Lechevalier. Pp. viii +430 , illustrated. London: Baillière, Tindall \& Cox. 1962. 144s.

A clinician approaches this beautifully produced monograph with awe. The third in a series on the actinomycetes, it is devoted to the antibiotics produced by these versatile and widespread micro-organisms. There are two sections: the first hundred pages or so discuss the nature and actions of antibiotics in general; the second part fills nearly three hundred pages of closely written type with detailed descriptions of each of the 400 antibiotics so far isolated. At least 30 have been used clinically, and these include the streptomycins, tetracyclines, erythromycins, chloramphenicol, neomycin, novobiocin and nystatin. Many of them, as is well known, were discovered in Waksman's laboratory.

Thus the first chapters are necessarily a review of the whole field of antibiotics, and make fascinating reading, none more so than the retelling of the history of chemotherapy. Clinical medicine, however, is but one of the fields in which antibiotics are used, and their place in animal feeding, the preservation of food, virus cultures, genetics and biochemistry is also discussed. The authors roundly condemn those who are cynical of the eventual staying power of antibiotics on account of drug resistance. They look forward to the discovery of antitumour (actinomycins have some activity) and anti-viral antibiotics among the vast ' gold mine' still to be tapped.

One minor criticism-the present book tends to be repetitive. With some tidying the first section would provide one of the best guides to present-day knowledge of antibiotics. Could the publishers be persuaded to publish it separately?

\section{The Molecular Basis of Neoplasia}

A Collection of Papers Presented at the Fifteenth Annual Symposium on Fundamental Cancer Research, 1961. Pp. 6r4, with illustrations. Austin, Texas: University of Texas Press. 1962. $\$ 10.50$.

The great majority of the 34 scientific papers in this book have very little to say specifically about neoplasia, the molecular basis of which remains obscure and a subject of speculation. Yet in so far as cancer is a 